\title{
Integration and Difference of Intercultural Communication in Idioms Translation
}

\author{
YUE Xin, YU Gao-feng \\ University of Shanghai for Science and Technology, Shanghai, China
}

\begin{abstract}
Idioms, composed of various linguistic characteristics, are frequently used by both Chinese and foreign people, making them perfect material to analyze different topics of intercultural communication. Through translations of idioms, we can easily find the integration and differences between English and Chinese idioms. In the process of translating, translators have to be acutely aware of not only the language differences, but also the associations and differences between the cultural background of two languages. By studying bilingual material after the translation is completed, re-comprehension of different cultures and their features can be acquired and it can feed back to our translation missions and foreign exchange activities. This paper aims to analyze the differences and integration of intercultural communication through examples of several idioms translation to illustrate the importance of intercultural communication view in translating and give translators a new prospective for translation strategies.
\end{abstract}

Keywords: intercultural communication, idioms translation, translation strategy

\section{Introduction}

The cognitive behaviour of races differs from each other because of the discrepancies in culture, languages, and environment. If two persons from different language background want to communicate with each other, the same language semiotic system is what they need to convey information (Tomasello, 1999, p. 97).

Language conveys the tradition, philosophy, customs, emotions and so on. As the essence of languages, idioms are one of the most frequently linguistic signs for people to express themselves. Usage and translation of this kind of sign can reflect many characteristics of two different languages because there are abundant elements embodied in the idioms, such as history, quotations, values, and rhetoric devices. Cultural connotations need to be interpreted primarily in the translation process because the words can only be understood in the same culture system and the mission of a translator is to create such a system (Nida, 2004, p. 146). When translating idioms, we transfer not only the linguistic signs, but also the culture patterns. So due to those excellent properties of idioms translation, the study of it is essential and meaningful for every language learner or enthusiast.

\section{Status and Features of Idioms and Their Translation}

\section{Status of Idioms and Their Translation}

Idioms include nearly everything within our cognitive domain, including language usage, culture, history,

YUE Xin, master candidate, College of Foreign Languages, University of Shanghai for Science and Technology, China.

YU Gao-feng, associate professor, M.A., College of Foreign Languages, University of Shanghai for Science and Technology, Shanghai, China. 
social etiquette and so on, which decides the importance of idioms in various study fields. From the prospective of intercultural communication, analysis of a certain idiom and its translation can help us learn a lot about the bilingual differences and the reason behind them. The definition, origin, usage, and the final translation version of an idiom are actually the re-comprehension of the domestic and foreign culture. Meanwhile, idioms appear in various occasions, both official and unofficial ones, and the translation of idioms is always a big problem because it is always hard to fully understand the meaning of idioms from another language culture so for people who are ready to be translators or in charge of foreign affairs and to study the idioms translation and the culture background behind is just like casting an anchor to windward (It is an idiom meaning to plan ahead for things that could happen in the future, the same as “未雨绸缪” in Chinese). Only in this way, they will not be tongue-tied when they encounter idioms in translation activities.

\section{Features of Idioms and Their Translation}

The most ideal translation for an idiom is to translate it into another idiom in another language but sharing the same meaning and form. Some perfect examples can be seen in the following Table 1.

Table 1

Perfect Examples of Idioms Translation

\begin{tabular}{ll}
\hline Source language & Target language \\
\hline 1. Merry meet, merry part & 好聚好散 \\
2. Knowledge is power & 知识就是力量 \\
3. Distance tests a horse's strength so time reveals a person's heart & 路遥知马力, 日久见心 \\
4. As fast as lightning & 快如闪电 \\
5. Seeing is believing & 眼见为实 \\
\hline
\end{tabular}

Table 1 has shown the most comfortable cases for translators because in those cases, images and their meaning of two languages are the same so what the translators need to do is to find the direct match for each case without too much worrying about the wrong understanding or translation.

However, language is rule-governed. Every structural level of human language is regulated by its own grammatical rules and principles and different language systems regulate their structures in different ways (CHEN \& Starosta, 2007). Thus, it is always extremely hard to translate one idiom from one language to another with its form and meaning perfectly reserved. In most cases, we cannot come up with a " $100 \%$ perfect" translation because the same image from two cultures represents two totally different meanings or the image in the source text simply does not exist in the target language, as is shown in the following Table 2.

Table 2

Examples of "Not Perfectly" Translated Idioms

\begin{tabular}{ll}
\hline Source language & Target language \\
\hline 1. The apple of one's eye & 掌上明珠 \\
2. He that sows the wind will reap the whirlwind & 玩火者必自焚 \\
3. To rain cats and dogs & 倾盆大雨 \\
4. To carry coals to Newcastle & 多此一举 \\
5. Hold a candle to the sun & 徒劳无益 \\
\hline
\end{tabular}

From Table 2, in view of the promptness and efficiency of idioms translation, there are another two translation strategies that can be chosen according to the source text. For cases like "the apple of one's eye" 
translated to “掌上明珠”, images representing “precious things” in the two cultures are different. “Apple” will never mean something treasured in Chinese people's mind so this image has to be changed to "pearl" for Chinese people to understand its meaning. The occasion also occurs in case No. 2.

For cases like No. 3 to 5, images like "cats and dogs" and "carry coals" cannot be matched with another image in Chinese culture so the original "image-to-image" translation construction has to be abandoned for reserving its true meaning.

To sum up, there are three kinds of situations and each has their own corresponding strategies:

(1) For the cases having the same meaning with the same image, translators only need to find the correct match of the source texts and use it;

(2) For cases with different meanings in the same image, translators should find the proper image from the target language;

(3) Last but not least, for cases without the peer-to-peer images in two languages, translators can only reserve its true meaning and sacrifice its "image-to-image" translation strategy.

\section{Difference of Intercultural Communication Hidden in English Idioms Translation}

From the two translation situations in the last part, differences of intercultural communication can be found. Culture also has social and ethnic attributes, without which culture cannot even exist. Each culture has a value system that is easy to understand for social groups of its own but hard to be perceived by social groups of other cultures. Therefore, effective translation, as an important way of communication, can be made only by understanding the differences between different cultures.

\section{Linguistic Signs}

From the perspective of semiotics, language is a symbol of consciousness including linguistic signs, world view, morality, religion, and thinking pattern. Language, as a symbolized system, can be divided into five categories: national consciousness symbol, social symbol, audio-visual symbol, materialized symbol, and regionalized symbol (Deutscher, 2010). National consciousness symbols reflect the ideology of one certain culture, for example, in Chinese, “天地” (Heaven and Earth) symbolizes the time and space while such term for the British people is the supremacy of God. Social symbols reflect linguistic signs such as national customs, interpersonal relationships, and lifestyle. The strongest audio-visual symbols are words related to sound and colour, figurative structure, and any other words or phrases transmitted through sound and vision. Materialized symbols refer to those words involved in material life, daily supplies, and technology. Regionalized symbols mainly reflect the geographical position, natural environment, and climate condition, such as “黑山白水” (which literally means black mountain and white water) in Chinese and "the land of promise" in English. As can be seen from the above, language, considered as a symbol, reflects the culture and customs of a nation.

From the perspective of language structure, idioms translation can easily be connected with other language usages, such as allusions, slang, and proverbs because the idiom itself is a giant composition of various fixed expressions with strong ethnic and regional characteristics (Abrahams, 1972, pp. 111-112). Since Chinese and English have undergone different social developments, the language vocabulary and usage they have must be different. Britain is an island country surrounded by the sea, while most of China is located in the interior of Asia. As a result, Chinese people often say “进退维谷” (which literally means being stuck in the valley) when they are in trouble, while British people say "be on the rocks". And when British people do something in vain, 
they will say “to fish in the air" or “to plough the air", while Chinese people will say “水中捞月” (which literally means to fish for the moon in the water) or “竹篮子打水一场空” (which literally means to draw water with a bamboo basket and achieving nothing).

The above examples are metaphorical expressions formed in different environments of ethnic culture, all of which is featured by distinct national characteristics.

\section{Thinking Pattern}

Thinking of human, a general and indirect response to the objective world, is one of the most precious functions of our brain. Thinking relies on language, without which thinking will lose its publicizing media. Thinking and language have close interaction but are unbalanced in power, in which the role of thinking on language is decisive. Therefore, the way of thinking determines the diversity of language expression.

Human thinking has both commonness and individuality. Individuality is a revealing fact about expression differences, which indeed stays in the way of exchanges among nations. For example, Chinese people will say “同舟共济” when they want to unite other people and share the success or obstacles. In English, a strikingly similar idiom "in the same boat" is often used wrongly by uninitiated translators as the translation of “同舟共 济". The fact is that those two idioms are completely different. If someone says "we are in the same boat" to you, it would not be good news because it means both of you are in the same unpleasant situation or dilemma and you have no choice but to face it! This shows that different nationalities have different modes of expression, though the content they say is almost the same and that is why translators encounter the same meaning but two different images in two cultures (the second situation in the last part). So, at this time, changing the images to the ones accepted by another language speaker is the best choice.

\section{Values}

Values formed in the process of social development vary from each other because of social, environmental, and traditional elements. Chinese culture is known for its splendid tradition of modesty, filial piety, and family harmony. Chinese people believe that the collectivity comes first, not the individual. Western people, however, pursue personal independence and measure one's life value by personal success.

A skilled bi-linguist must also be a bi-cultural learner. In different languages, words with the same linguistic meanings may have different pragmatic meaning. For example, “老师” (Lao Shi) in Chinese and "teacher" in English both refer to "a person who teaches, usually as a job at a school or similar institution" (Boye, 1996, pp. 44-45). However, from the pragmatic level, teacher is only limited to the above meaning in Western countries while Chinese people prefer "Lao Shi" to call anyone they respect. This gives us a significant hint: When we translate some idioms involving the elements that are easily misunderstood, we need to reconsider our final version or add additional notes to make the whole thing clear. For example, if “胸有成 竹" is merely translated into "have a bamboo in one's mind", it will be extremely difficult for foreigners to connect "bamboo" with confidence because most of them do not know the story and in Western values system, "confidence" is connected with "lion" or "eagle" and their living environment does not have too many bamboos. So the proper translation version may be "to have a well-thought-out plan" or "behave like a painter having a bamboo in his mind before he draws it".

To make it clear, those three differences are the main reasons for the explanation of the three situations in the last part; and it does not mean that each reason is just corresponded with one situation. Sometimes, maybe two or three of those elements will act together due to complexity of the source text. 


\section{Integration of Intercultural Communication Hidden in English Idioms Translation}

Different culture has integrated each other as the globalization is deepening. After reading more and more translation texts with elements from both languages, people tend to accept and even love features from other culture and integration is thus formed.

\section{Integration of Images}

In the process of intercultural communication between China and foreign countries, more and more images from other culture can be accepted by us now from various media, such as translated versions of fairy tales, literature, and songs. Many originally strange images and metaphors from other culture are now common for us. Meanwhile, as we are further exposed to the foreign culture and languages, we could find numerous similar signs or images in both languages. Those two kinds of phenomena can be seen in many cases and some of them are listed in the following Table 3.

Table 3

Examples of Image Integration

\begin{tabular}{ll}
\hline Source language & Target language \\
\hline 1. Crocodile tears & 鳄鱼的眼泪 \\
2. Money makes the mare go & 有钱能使鬼推磨 \\
3. To kill two birds with one stone & 一石二鸟 \\
4. Men may meet but mountains never & 人与人总会相遇, 山与山注定无缘 \\
5. Trojan horse & 特洛伊木而 \\
\hline
\end{tabular}

From those examples, an interesting phenomenon can be seen that though we, as two persons from two different culture background, may live in two totally different environments, when we need to express certain meanings, we will use the same matter or image to connote our feelings. "Crocodiles", "birds", and even the "mare" in China are of course not the same as those in Western countries, but when we need to create metaphors of certain feelings or emotions, we end up using the same things as our images.

\section{Integration of Sentence Formation and Building}

In terms of sentence formation, one of the most obvious integration is the fixed structure. Each internal part of a certain idiom is fixed, especially for idioms with numbers. For example, Chinese people say “一诺千 金” to emphasize the importance of keeping someone's promise. And we need to know that “一” in this idiom does not really mean "one" and "千” (a thousand) actually means "a lot". The whole sentence literally means that the value of one's promise is equal to a lot of money. However, in practical use, no matter how many promise sentences you have made, you must use "—" (one) here. Other numeric character will cause confusion once in use. Likewise, there are also many other Chinese numeric characters can express "many”, like “九” (nine) or “万" (which is literally equal to ten thousands but can mean the number more than that in practical usage), and many Chinese characters represent “valuable things" just like “鼎” (an exquisite cauldron often used by royal family) or “银” (silver) but we can only and must use “一”, “千”, and “金” here. The same condition occurs in English idioms and translated version. “A stitch in time saves nine” (及时缝一针可免缝九 针) is a good case in point. We could find that "A" and "nine" appear here again and they definitely cannot be changed by other words, either. In practical usage, there are always more than "a stitch" we can make up and "nine" is not always the exact number, of course but "A" and "nine" are fixed here and we cannot change them by our will. 


\section{Conclusion}

Integration and differences of intercultural communication can be seen in idioms translation, which gives us an overall understanding of the cultural background and at the same time sets the hurdles for people to understand the idioms from other languages because it is difficult to figure out whether the image or word usage in a foreign idiom is similar to that of another one. Through these studies, it could be found that due to different cultural background, many discrepancies in values and thinking patterns exist between English idioms and their translation version. It is universally acknowledged that understanding is the fundamental basis of translation and the translation is also the sublimation process of understanding. So whether our purpose is to learn the intercultural communication knowledge or to learn idioms translation skills, analysis of difference and integration examples like what this paper has done is very necessary and helpful for us to improve our relative abilities.

\section{References}

Abrahams, R. D. (1972). Proverbs and proverbial expressions (pp. 111-112). Chicago: The University of Chicago Press.

Boye, L. D. M. (1996). NTC's dictionary of China's cultural code words (pp. 45-46). Linconwood Illinois: NTC Publishing Group.

CHEN, G. M., \& Starosta, W. J. (2007). Foundations of intercultural communication (pp. 144-151). Shanghai: Shanghai Foreign Language Education Press.

Deutscher, G. (2010). Through the language glass: Why the world looks different in other language (pp. 45-49). New York: Metropolitan Books.

Nida, E. A. (2004). Toward a science of translation. Shanghai: Shanghai Foreign Language Education Press.

Tomasello, M. (1999). The cultural origins of human cognition (pp. 8-14). New York: Harvard University Press. 